\section{Pengaruh Stress Kerja, Promosi Jabatan dan Budaya Organisasi Terhadap Produktivitas Kerja Karyawan PT Jasamarga Related Business}

\author{
Degatha Raginisa ${ }^{1}$, Renny Husniati ${ }^{2}$, Zackharia Rialmi ${ }^{3}$ \\ Fakultas Ekonomi dan Bisnis Universitas Pembangunan Nasional Veteran \\ Jakarta Email: draginisa@gmail.com ${ }^{1}$, rennyhusniati@upnvj.ac.id ${ }^{2}$, \\ zac_rialmi@upnvj.ac.id ${ }^{3}$
}

\begin{abstract}
This research is a quantitative that aims to determine the influence of job stress, job promotion and organizational culture on employee work productivity at PT Jasamarga Related Business. This research used a sample size of 60 respondents who were all employees of the head office of PT Jasamarga Related Business. The analysis technique in this research is to use the coefficient of determination test, $t$ test (partial) and F test (simultaneous) using SPSS version 25 software. The test result show that (1) job stress has a significant effect on the employee work productivity of PT Jasamarga Related Business, (2) job promotion has a significant effect on the employee work productivity of PT Jasamarga Related Business, (3) organizational culture has a significant effect on employee work productivity of PT Jasamarga Related Business, (4) job stress, job promotion and organizational culture simultaneously have a significant effect on employee work productivity of PT Jasamarga Related Business.
\end{abstract}

Keywords: job stress, job promotion, organizational culture and work productivity.

\begin{abstract}
ABSTRAK
Penelitian ini merupakan penelitian kuantitatif yang bertujuan untuk mengetahui pengaruh stress kerja, promosi jabatan dan budaya organisasi terhadap produktivitas kerja karyawannPT Jasamarga Related Business. Penelitian ini menggunakan ukuran sampel sebanyak 60 orang responden yang merupakan keseluruhan dari karyawan kantor pusat PT Jasamarga Related Business. Teknik analisa dalam penelitian ini adalah menggunakan Uji Koefisien Determinasi, Uji t (parsial) dan Uji F (Simultan) menggunakan software SPSS versi 25. Hasil pengujian diperoleh hasil (1) stress kerja berpengaruh signifikan terhadap produktivitas kerja karyawan PT Jasamarga Related Business, (2) promosi jabatan berpengaruh signifikan terhadap produktivitas kerja karyawannPT Jasamarga Related Business, (3) budaya organisasi berpengaruh signifikan terhadap produktivitas kerjaakaryawan PT Jasamarga Related Business, (4) stress kerja, promosi jabatan dan budaya organisasi berpengaruh signifikan secara bersama-sama terhadap produktivitas kerja karyawan PT Jasamarga Related Business.
\end{abstract}

Kata Kunci: stress kerja, promosi jabatan, budaya organisasi dan produktivitas kerja.

\section{PENDAHULUAN}

Produktivitas merupakan suatu motif atau cara untuk memaksimalkan hasil kerja dengan biaya yang seminimal mungkin. Karyawan merupakan faktor tertinggi penentu apakah sebuah organisasi atau perusahaan dapat menghasilkan hasil yang maksimal atau tidak yang merupakan buah dari poduktivitas karyawannya. Dalam melihat produktivitas karyawannya, JMRB menggunakan penilaian kinerja karyawannya untuk mengetahui sejauh mana karyawan tersebut produktif dalam bekerja.
Job Stress, Job

Promotion,

Organizational

Culture and Work

Productivity

Submitted:

Accepted: JUNI 2021

\title{
JIMKES
}


Job Stress, Job

Promotion,

Organixational

Culture and Work

Productivity

\section{8}

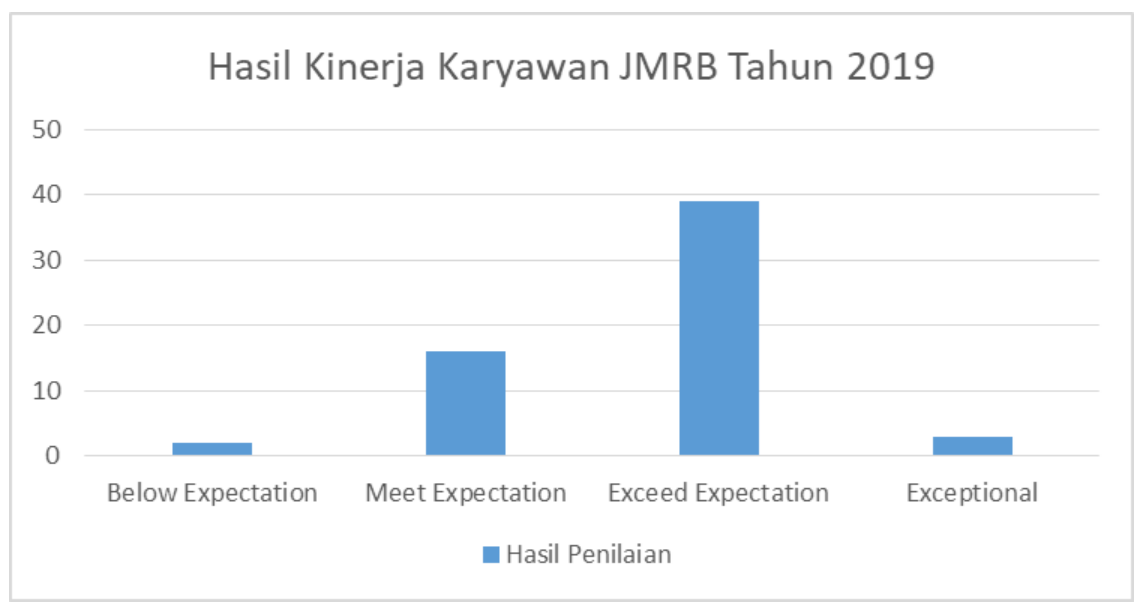

Sumber: PT Jasamarga Related Business

Gambar 1 Grafik Kinerja Karyawan JMRB Tahun 2019 (Jumlah Karyawan)

Berdasarkan data yang telah disajikan, sebanyak 30\% karyawan JMRB memiliki kinerja di bawah dari yang diharapkan dan sesuai dengan standar, yaitu berada di penilaian Below Expectation dan Meet Expectation (18 karyawan) dan sebanyak 65\% karyawan JMRB memiliki penilaian kinerja rata-rata atau Exceed Expectation (39 karyawan) serta sebanyak 5\% karyawan JMRB memiliki penilaian melebihi harapan atau Exceptional (3 karyawan). Hal ini menjadi perhatian karena sebanyak 30\% karyawan JMRB memiliki kinerja yang di bawah rata-rata dan sesuai dengan standar sedangkan hanya 5\% karyawan JMRB yang memiliki kinerja di atas rata-rata. Jika dibiarkan terusmenerus maka produktivitas kerja dan output yang dihasilkan JMRB perlahan-lahan akan menurun dan tidak stabil.

Berdasarkan data di atas, maka dapat disimpulkan produktivitas karyawan JMRB masih di bawah dan setara dengan nilai rata-rata atau belum optimal. Hal ini dapat dilihat bahwa mayoritas karyawannya masih belum berada di titik maksimal dalam produktivitas tersebut. Padahal, kenyataan dilapangan sangat memungkinkan karyawannya bisa memaksimalkan produktivitas yang dimilikinya.

Untuk mencapai nilai produktivitas yang maksimal atau yang diharapkan tidaklah mudah. Seorang karyawan yang memiliki target pekerjaan yang tinggi atau tuntunan produktivitas yang tinggi ikut disertai dengan perasaan stress. Menurut Selhub (2019, p.17) mengatakan bahwa stress merupakan sesuatu yang terjadi di dalam tubuh yang bisa menganggu baik secara fisik maupun mental.

Karyawan JMRB dinilai memiliki stress dalam bekerja dikarenakan adanya tuntunan pekerjaan yang cukup tinggi dan saat ini sedang memasuki masa pandemic Covid-19 yang berarti karyawan merasa cemas atas kesehatan dirinya dan keluarganya. Meskipun pembagian jadwal antara karyawan yang melakukan Work From Office (WFO) dengan karyawan yang melakukan Work From Home (WFH) sudah dilakukan, namun beberapa karyawan yang sedang berada di jadwal WFH tetap datang ke kantor dengan alasan hanya bisa dikerjakan dikantor. Dengan adanya kondisi tersebut, maka karyawan lebih rentan untuk mengalami stress kerja. Namun, stress kerja yang memiliki pengaruh positif terhadap seseorang dapat menjadi pemicu atau dasar dari seseorang untuk dapat bekerja lebih produktif lagi. Hal ini dikarenakan sifat dari stress berdampak positif adalah memotivasi dari adanya suatu kewajiban atau beban yang dimilikinya. Dengan kata lain, stress kerja dapat mempengaruhi baik secara negatif maupun positif.

Selain stress kerja, hal yang mempengaruhi selanjutnya dalam produktivitas karyawan adalah promosi jabatan. Siswanto $(2019, \mathrm{hlm} .18)$ berpendapat bahwa promosi jabatan merupakan suatu pembuktian atau penghargaan bahwa suatu organisasi telah menghargai para karyawannya yaitu dengan perpindahan karyawan dengan jabatan yang lebih tinggi. Program promosi yang diberikan oleh JMRB kepada karyawan tetap adalah dengan menaikkan jabatan atau pangkat karyawan tersebut. Sedangkan program promosi jabatan bagi karyawan kontrak adalah dengan menaikkan jabatan karyawan 
tersebut atau dengan mengubah status karyawan tersebut yang sebelumnya karyawan kontrak menjadi karyawan tetap.

JMRB dinilai masih kurang dalam mengembangkan karyawannya dalam program promosi jabatan, hal ini dikarenakan program promosi yang tidak menentu kapan akan dilakukan menyesuaikan sesuai dengan kebutuhan JMRB saat tertentu. Dengan adanya sistem yang seperti ini, membuat karyawan JMRB menjadi tidak semangat dalam bekerja, hal ini dikarenakan tidak adanya dorongan untuk bekerja dan meningkatkan produktivitas yang disebabkan oleh program promosi jabatan.

Tabel 1 Jumlah Karyawan Kontrak JMRB

\begin{tabular}{|l|l|l|}
\hline No & Periode Kontrak & Jumlah Karyawan \\
\hline 1 & $<1$ Tahun & 6 Karyawan \\
\hline 2 & 1 Tahun & 7 Karyawan \\
\hline 3 & 2 Tahun & 8 Karyawan \\
\hline 4 & 3 Tahun & 5 Karyawan \\
\hline 5 & 4 Tahun & 6 Karyawan \\
\hline 6 & $>4$ Tahun & 1 Karyawan \\
\hline \multicolumn{2}{|l|}{ Jumlah Karyawan Kontrak } & 33 Karyawan \\
\hline
\end{tabular}

Selain itu, jumlah karyawan yang statusnya kontrak sebanyak 33 karyawan dari 60 karyawan di dalam JMRB, hal ini berarti masih ada 55\% karyawan kontrak atau setengah lebih dari total karyawan JMRB dan karyawan kontrak tersebut telah memiliki masa kontrak yang cukup lama, padahal beberapa karyawan memiliki nilai produktivitas dan kinerja yang baik. Sehingga, permasalahan tidak adanya program promosi jabatan yang teratur akan mempengaruhi produktivitas kerja karyawan yang diakibatkan oleh kurangnya promosi jabatan.

Faktor lainya yang mempengaruhi adalah budaya organisasi. Budaya suatu organisasi menurut Eldridge dan Combie (Armstrong \& Taylor, 2014 p.120) berisi mengenai norma, nilai, kepercayaan dan cara berperilaku suatu organisasi dalam menyelesaikan sesuatu. Budaya organisasi sangat penting bagi suatu organisasi, karena di dalamnya menyangkut sisi internal organisasi antara lain bagaimana cara berkembang, menyelesaikan sesuatu dan suatu hal yang biasa dilakukan.

Menurut hasil wawancara dengan General Manager SDM dan Umum (SDMU), budaya yang terlihat di lingkungan kerja JMRB adalah karyawan yang bisa bekerjasama dengan baik dan terstruktur, baik satu divisi maupun antar divisi lainya. Namun, budaya yang dimiliki oleh karyawan JMRB pula adalah pada saat sore hari banyak karyawan yang kurang produktif atau kurang maksimal dalam bekerja, hal ini dikarenakan banyak karyawan di sore hari yang sudah mengurangi intensitas bekerjanya bahkan cenderung untuk mengobrol kepada sesama karyawan. Hal ini bisa mempengaruhi tingkat produktivitas karyawan tersebut, hal ini dikarenakan seharusnya jam tersebut masih bisa dilakukan bekerja secara produktif.

Banyak penelitian terdahulu terkait dengan variabel stress kerja, promosi jabatan dan budaya organisasi (Anita 2017; Hoboubi et al. 2017; Margahana and Sari 2019; Sasuwe et al. 2018; de Sivatte et al. 2015). Tujuan dari penelitian ini adalah (1) untuk mengetahui dan membuktikan pengaruh stress kerja terhadap produktivitas kerja karyawan PT Jasamarga Related Business, (2) untuk mengetahui dan membuktikan pengaruh promosi jabatan terhadap produktivitas kerja karyawan PT Jasamarga Related Business, (3) untuk mengetahui dan membuktikan pengaruh budaya organisasi terhadap produktivitas kerja karyawan PT Jasamarga Related Business dan (4) untuk mengetahui dan membuktikan pengaruh stress kerja, promosi jabatan dan budaya organisasi secara bersama-sama terhadap produktivitas kerja karyawan PT Jasamarga Related Business.
Job Stress, Job

Promotion,

Organizational

Culture and Work

Productivity

269 
Job Stress, Job

Promotion,

Organixational

Culture and Work

Productivity
Model Pemikirian

Berdasarkan pemaparan teori di atas, maka model penelitian yang dapat dilihat pada gambar dibawah ini:

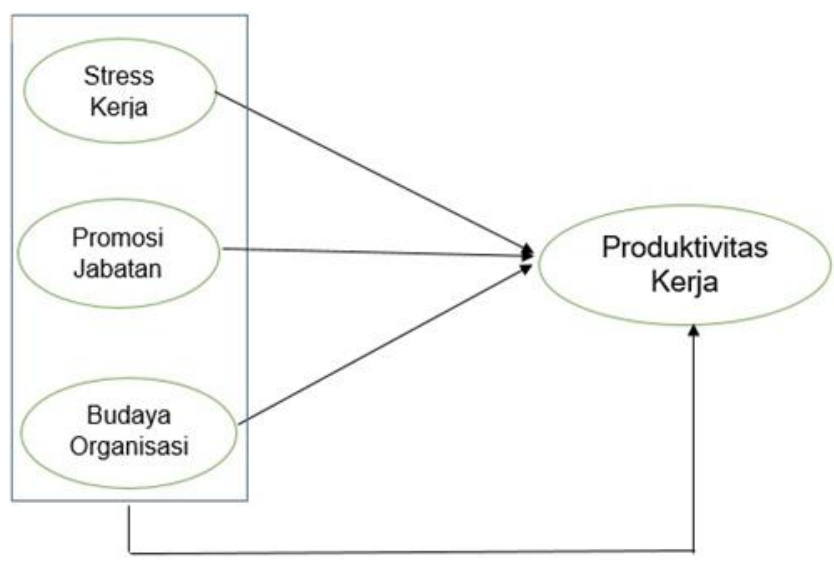

Gambar 2 Model Penelitian Empiris

Hipotesis Penelitian

1. Diduga stress kerja berpengaruh terhadap produktivitas kerja karyawan PT. Jasamarga Related Business.

2. Diduga promosi jabatan berpengaruh terhadap produktivitas kerja karyawan PT. Jasamarga Related Business.

3. Diduga budaya organiasi berpengaruh terhadap produktivitas kerja karyawan PT. Jasamarga Related Business.

4. Diduga stress kerja, promosi jabatan dan budaya organisasi berpengaruh secara bersama-sama terhadap produktivitas kerja karyawan PT. Jasamarga Related Business.

\section{METODE PENELITIAN}

Definisi Operasional

Definisi operasional yang menjelaskan keseluruhan variabel dari penelitian ini adalah sebagai berikut:

1. Produktivitas Kerja (Y). Produktivitas kerja merupakan skor penilaian yang di dapat dari skala pengukuran jawaban responden yang diukur menggunakan indikator kuantitas kerja, kualitas kerja dan ketepatan waktu.

2. Stress Kerja (X1). Stress kerja merupakan skor penilaian yang di dapat dari skala pengukuran jawaban responden yang diukur menggunakan indikator physiological, psychologic, behaviour.

3. Promosi Jabatan (X2). Promosi jabatan merupakan skor penilaian yang di dapat dari skala pengukuran jawaban responden yang diukur menggunakan indikator komunikatif, intelektual, memiliki visi yang baik, beprestasi, disiplin, kerjasama, kejujuran, merasa memiliki dan kesetiaan.

4. Budaya Organisasi (X3). Budaya organisasi merupakan skor penilaian yang di dapat dari skala pengukuran jawaban responden yang diukur menggunakan indikator pelaksanaan norma, pelaksanaan nilai-nilai, kepercayaan danfilfasat, pelaksaan kode etik, pelaksaan seremoni dan sejarah organisasi.

\section{Populasi dan Sampel}

Populasi untuk mengambil data penelitian adalah karyaan PT Jasamarga Related Business sebanyak 60 karyawan. Dan sampel yang dituju untuk mengambil data adalah keseluruhan karyawan dari kantor pusat PT Jasamarga Related Business sebanyak 60 karyawan atau dengan kata lain adalah menggunakan sampel jenuh.

Jenis dan Sumber Data 
Jenis data yang digunakan adalah data kuantitatif, sehingga sumber data primer yang digunakan adalah metode kuisioner yang disebar ke seluruh karyawan PT Jasamarga Related Business. Selain itu, data sekunder yang digunakan adalah literatur atau buku dan jurnal yang berkaitan dengan variabel yang dibahas.

\section{Pengumpulan Data}

Teknik pengumpulan data yang digunakan dalam penelitian ini adalah Angket (Kuisioner). Angket atau kuisioner akan diberikan kepada karyawan PT Jasamarga Related Business. Wawancara. Wawancara akan dilakukan kepada General Manager Sumber Daya Manusia dan Umum (SDMU) PT Jasamarga Related Business. Hal ini dikarenakan General Manager SDMU ini dinilai memumpuni untuk memberikan informasi secara nyata dan benar terkait hal yang terjadi di lapangan.Dokumentasi. Dokumentasi disini dapat berupa profile perusahaan, literatur tertentu yang berkaitan dengan penelitian ataupun data karyawan.

Dalam penelitian ini, skala pengukuran yang digunakan adalah skala likert, dimana rentang skor yang digunakan adalah sebagai berikut:

Tabel 2 Skala Pengukuran Likert

\begin{tabular}{|c|l|c|}
\hline Pernyataan & \multicolumn{1}{|c|}{ Pengertian } & Skor / Angka \\
\hline STS & Sangat Tidak Setuju & 1 \\
\hline TS & Tidak Setuju & 2 \\
\hline N & Netral & 3 \\
\hline S & Setuju & 4 \\
\hline SS & Sangat Setuju & 5 \\
\hline
\end{tabular}

Sumber: Radjab dan Jam'an (2017)

Dalam penyebaran kuisioner, diperlukan pernyataan yang di dalamnya berisi indikator-indikator yang sesuai variabel agar data yang di dapatkan dapat menjawab hipotesis di penelitian ini. Berikut ini merupakan kisi-kisi instrument yang termuat di dalam kuisioner:

Tabel 3 Kisi-kisi Instrument Variabel

\begin{tabular}{|c|c|c|c|}
\hline Variabel & Indikator & $\begin{array}{c}\text { Butir } \\
\text { Pertanyaan } \\
\end{array}$ & Jumlah \\
\hline \multirow{3}{*}{$\begin{array}{l}\text { Produktivitas } \\
\text { Kerja (Y) }\end{array}$} & Kuantitas Kerja & $1,2,3$ & 3 \\
\hline & Kualitas Kerja & $4,5,6$ & 3 \\
\hline & Ketepatan Waktu & $7,8,9$ & 3 \\
\hline \multirow{3}{*}{ Stress Kerja (X1) } & Physiological & $10,11,12$ & 3 \\
\hline & Psychologic & $13,14,15$ & 3 \\
\hline & Behaviour & $16,17,18$ & 3 \\
\hline \multirow{9}{*}{$\begin{array}{l}\text { Promosi Jabatan } \\
\text { (X2) }\end{array}$} & Komunikatif & 19 & 1 \\
\hline & Intelektual & 20 & 1 \\
\hline & Memiliki Visi & 21 & 1 \\
\hline & Berprestasi & 22 & 1 \\
\hline & Disiplin & 23 & 1 \\
\hline & Kerjasama & 24 & 1 \\
\hline & Kejujuran & 25 & 1 \\
\hline & Merasa Memiliki & 26 & 1 \\
\hline & Kesetiaan & 27 & 1 \\
\hline \multirow{6}{*}{$\begin{array}{c}\text { Budaya } \\
\text { Organisasi (X3) }\end{array}$} & Pelaksanaan Norma & 28,29 & 2 \\
\hline & Pelaksanaan Nilai-nilai & 30,31 & 2 \\
\hline & Kepercayaan dan Filsafat & 32,33 & 2 \\
\hline & Pelaksanaan Kode Etik & 34,35 & 2 \\
\hline & Pelaksanaan Seremoni & 36,37 & 2 \\
\hline & Sejarah Organisasi & 38,39 & 2 \\
\hline
\end{tabular}

Sumber: Data diolah, 2020.
Job Stress, Job

Promotion,

Organizational

Culture and Work

Productivity 
Job Stress, Job

Promotion,

Organixational

Culture and Work

Productivity
Deskripsi Data Responden

Tabel 4 Data Responden Berdasarkan Jenis Kelamin

\begin{tabular}{|c|c|c|}
\hline Jenis Kelamin & Frekuensi & Presentase \\
\hline Laki-laki & 35 & 58.30 \\
\hline Perempuan & 25 & 41.70 \\
\hline Total & 60 & 100 \\
\hline
\end{tabular}

Sumber: Data Diolah, 2020.

Berdasarkan tabel 4 di atas, karyawan yang berjenis kelamin laki-laki sebanyak 35 responden atau $58.30 \%$ dan perempuan sebanyak 25 responden atau $41.70 \%$. Hal ini dapat dikatakan bahwa jumlah karyawan laki-laki di PT Jasamarga Related Business lebih banyak dibandingkan dengan jumlah karyawan perempuan.

Tabel 5 Masa Kerja Responden

\begin{tabular}{|l|l|l|}
\hline Jenis Kelamin & Frekuensi & Presentase \\
\hline$<\mathbf{1}$ Tahun & 6 & 10 \\
\hline $\mathbf{1}-\mathbf{2}$ Tahun & 22 & 37 \\
\hline 3 - 4 Tahun & 19 & 32 \\
\hline$>$ 5 Tahun & 13 & 22 \\
\hline Total & 60 & 100 \\
\hline
\end{tabular}

Sumber: Data Diolah, 2020.

Berdasarkan tabel 5 di atas, responden yang memiliki masa kerja $<1$ tahun berjumlah 6 responden atau $10 \%$, untuk yang memiliki masa kerja antara 1 sampai dengan 2 tahun berjumlah 22 responden atau 37\%, kemudian yang memiliki masa kerja 3 sampai 4 tahun berjumlah 19 responden atau $32 \%$ dan yang memiliki masa kerja lebih dari 5 tahun berjumlah 13 responden atau 22\%. Hal ini dapat dikatakan bahwa karyawan di PT Jasamarga Related Business paling banyak mempunyai masa kerja antara 1 sampai dengan 2 tahun.

Tabel 6 Jabatan Responden

\begin{tabular}{|l|c|l|}
\hline \multicolumn{1}{|c|}{ Jenis Kelamin } & Frekuensi & Presentase \\
\hline Manager & 22 & 37 \\
\hline Assisten Manager & 11 & 18 \\
\hline Officer dan Staff & 27 & 45 \\
\hline Total & 60 & 100 \\
\hline
\end{tabular}

Sumber: Data Diolah, 2020.

Berdasarkan tabel 6 di atas, responden yang memiliki jabatan manager berjumlah 22 atau $37 \%$, sementara yang memiliki jabatan assisten manager berjumlah 27 atau $18 \%$ dan yang memiliki jabatan sebagai officer dan staff berjumlah 27 atau 45\%. Hal ini dapat dikatakan bahwa PT Jasamaraga Related Business paling banyak memiliki karyawan dengan jabatan sebagai officer dan staff.

Analisis Data Deskriptif

Tabel 7 Analisis Deskriptif Jawaban Responden Variabel Produktivitas Kerja (Y)

\begin{tabular}{cccllllll}
\hline Pernyataan & Mean & Mode & \multicolumn{6}{c}{ Presentase Frekuensi Jawaban (\%) } \\
\cline { 5 - 9 } & & & $\mathbf{1}$ & $\mathbf{2}$ & $\mathbf{3}$ & $\mathbf{4}$ & $\mathbf{5}$ & Total \\
\hline Y.1.1 & 4.13 & 4 & 0 & 3.3 & 16.7 & 43.3 & 36.7 & 100 \\
\hline Y.1.2 & 4.07 & 4 & 1.7 & 3.3 & 13.3 & 50.0 & 31.7 & 100 \\
\hline Y.2.1 & $\mathbf{4 . 2 7}$ & 5 & 0 & 1.7 & 15 & 38.3 & 45 & 100 \\
\hline Y.2.2 & 4.02 & 4 & 0 & 5 & 15 & 53.3 & 26.7 & 100 \\
\hline Y.2.3 & $\mathbf{3 . 8 0}$ & 4 & 3.3 & 5 & 20 & 51.7 & 20 & 100 \\
\hline Y.3.1 & 4.18 & 4 & 0 & 5 & 11.7 & 43.3 & 40 & 100 \\
\hline Y.3.2 & 3.95 & 4 & 0 & 1.7 & 28.3 & 43.3 & 26.7 & 100 \\
\hline Y.3.3 & 4.00 & 4 & 0 & 6.7 & 18.3 & 43.3 & 31.7 & 100
\end{tabular}

Sumber: Data Diolah, SPSS, 2020.

Berdasarkan tabel 7 di atas, rata-rata terendah yaitu karyawan PT Jasamarga Related 
Business merasa setuju dengan pengetahuan dan rekan kerja dapat membantu saya dalam menyelesaikan pekerjaan dengan baik. Sementara rata-rata tertinggi yaitu karyawan PT Jasamarga Related Business merasa sangat setuju pada hasil pekerjaan yang akan menentukan kemajuan karir kedepanya. Hal ini dapat menjelaskan bahwa karyawan PT Jasamarga Related Business sangat menyetujui bahwa pekerjaan yang mereka kerjakan saat ini akan sangat berpengaruh terhadap kelangsungan kehidupan karir atau pekerjaan mereka.

Tabel 8 Analisis Deskriptif Jawaban Responden Variabel Stress Kerja (X1)

\begin{tabular}{|c|c|c|c|c|c|c|c|c|}
\hline \multirow[t]{2}{*}{ Pernyataan } & \multirow[t]{2}{*}{ Mean } & \multirow[t]{2}{*}{ Mode } & \multicolumn{6}{|c|}{ Presentase Frekuensi Jawaban (\%) } \\
\hline & & & 1 & 2 & 3 & 4 & 5 & Total \\
\hline $\mathrm{X} 1.1 .1$ & 3.25 & 4 & 5 & 20 & 28.3 & 38.3 & 8.3 & 100 \\
\hline X1.1.2 & 2.63 & 2 & 21.7 & 28.3 & 25 & 15 & 10 & 100 \\
\hline X1.1.3 & 3.00 & 3 & 10 & 21.7 & 33.3 & 28.3 & 6.7 & 100 \\
\hline $\mathrm{X} 1.2 .1$ & 4.03 & 4 & 0 & 1.7 & 20 & 51.7 & 26.7 & 100 \\
\hline X1.2.3 & 3.07 & 3 & 10 & 20 & 31.7 & 30 & 8.3 & 100 \\
\hline $\mathrm{X} 1.3 .2$ & 2.67 & 2 & 20 & 28.3 & 21.7 & 25 & 5 & 100 \\
\hline $\mathrm{X} 1.3 .3$ & 2.90 & 4 & 13.3 & 23.3 & 26.7 & 33.3 & 3.3 & 100 \\
\hline
\end{tabular}

Sumber: Data Diolah, SPSS, 2020.

Berdasarkan tabel 8 di atas, rata-rata terendah yaitu karyawan PT Jasamarga Related Business menjawab tidak setuju bahwa melakukan kegiatan olahraga sebelum bekerja agar bisa lebih fokus dalam bekerja. Sementara rata-rata tertinggi yaitu karyawan PT Jasamarga Related Business menjawab setuju bahwa mereka mendapati kepuasan kerja, baik hubungan dengan sesama karyawan maupun dengan bos mereka secara langsung. Hal ini dapat dikatakan bahwa responden atau karyawan PT Jasamarga Related Business menyetujui bahwa mereka mendapati kepuasan kerja saat melakukan pekerjaan di dalam PT Jasamarga Related Business tersebut.

Tabel 9 Analisis Deskriptif Jawaban Responden Variabel Promosi Jabatan (X2)

\begin{tabular}{lllllllll}
\hline Pernyataan & Mean & Mode & \multicolumn{7}{c}{ Presentase Frekuensi Jawaban (\%) } & \\
\cline { 3 - 9 } & & & $\mathbf{1}$ & $\mathbf{2}$ & $\mathbf{3}$ & $\mathbf{4}$ & $\mathbf{5}$ & Total \\
\hline $\mathbf{X 2 . 1 . 1}$ & 4.32 & 4 & 0 & 0 & 6.7 & 55 & 38.3 & 100 \\
\hline $\mathbf{X 2 . 2 . 1}$ & 4.20 & 4 & 0 & 3.3 & 13.3 & 43.3 & 40 & 100 \\
\hline $\mathbf{X 2 . 3 . 1}$ & 4.03 & 4 & 0 & 3.3 & 16.7 & 53.3 & 26.7 & 100 \\
\hline $\mathbf{X 2 . 4 . 1}$ & 3.97 & 4 & 0 & 5 & 21.7 & 45 & 28.3 & 100 \\
\hline $\mathbf{X 2 . 5 . 1}$ & 3.87 & 4 & 0 & 6.7 & 21.7 & 50 & 21.7 & 100 \\
\hline $\mathbf{X 2 . 6 . 1}$ & 4.35 & 4 & 0 & 1.7 & 5 & 50 & 43.3 & 100 \\
\hline $\mathbf{X 2 . 7 . 1}$ & 4.23 & 4 & 0 & 1.7 & 13.3 & 45 & 40 & 100 \\
\hline $\mathbf{X 2 . 8 . 1}$ & $\mathbf{4 . 3 7}$ & 4 & 0 & 1.7 & 5 & 48.3 & 45 & 100 \\
\hline $\mathbf{X 2 . 9 . 1}$ & $\mathbf{3 . 8 5}$ & 4 & 0 & 8.3 & 25 & 40 & 26.7 & 100 \\
\hline
\end{tabular}

Sumber: Data Diolah, SPSS, 2020.

Berdasarkan tabel 9 di atas, rata-rata terendah yaitu karyawan PT Jasamarga Related Business menjawab setuju bahwa pribadi yang mempunyai rasa kesetiaan akan lebih mudah untuk dapat dipromosikan. Sedangkan rata-rata tertinggi yaitu karyawan PT Jasamarga Related Business menjawab setuju bahwa merasa nyaman dan memiliki ditempat kerja akan membuat hasil pekerjaan menjadi lebih baik. Hal ini dapat memberi gambaran bahwa karyawan PT Jasamarga Related Business memiliki pandangan dan menyetujui bahwa kenyamanan ditempat kerja akan mempengaruhi seberapa protuktif seseorang dan hasil kerja yang didapatkan.

Tabel 10 Analisis Deskriptif Jawaban Responden Variabel Budaya Organisasi (X3)

Pernyataan Mean Mode Presentase Frekuensi Jawaban (\%)

\begin{tabular}{|c|c|c|c|c|c|c|c|c|}
\hline & & & 1 & 2 & 3 & 4 & 5 & Total \\
\hline X3.1.1 & 4.30 & 4 & 0 & 1.7 & 10 & 45 & 43.3 & 100 \\
\hline X3.1.2 & 4.10 & 4 & 0 & 1.7 & 13.3 & 58.3 & 26.7 & 100 \\
\hline X3.2.1 & 4.82 & 4 & 0 & 5 & 30 & 43.3 & 21.7 & 100 \\
\hline
\end{tabular}




\begin{tabular}{llllllllll} 
Job Stress, Job & $\mathbf{X 3 . 2 . 2}$ & 3.72 & 4 & 0 & 10 & 21.7 & 55 & 13.3 & 100 \\
\cline { 2 - 10 } $\begin{array}{l}\text { Promotion, } \\
\text { Organixational }\end{array}$ & $\mathbf{X 3 . 3 . 1}$ & $\mathbf{3 . 2 8}$ & 4 & 10 & 11.7 & 28.3 & 40 & 10 & 100 \\
\cline { 2 - 10 } $\begin{array}{l}\text { Culture and Work } \\
\text { Productivity }\end{array}$ & $\mathbf{X 3 . 4 . 1}$ & 4.10 & 4 & 0 & 5 & 10 & 55 & 30 & 100 \\
\cline { 2 - 10 } & $\mathbf{X 3 . 5 . 1}$ & 3.33 & 4 & 0 & 0 & 10 & 46.7 & 43.3 & 100 \\
\cline { 2 - 10 } & $\mathbf{X 3 . 5 . 2}$ & 3.40 & 4 & 0 & 16.7 & 35 & 40 & 8.3 & 100 \\
$\mathbf{2 7 4}$ & $\mathbf{X 3 . 6 . 1}$ & 3.68 & 4 & 0 & 11.7 & 23.3 & 50 & 15 & 100 \\
\hline
\end{tabular}

Sumber: Data Diolah, SPSS, 2020.

Berdasarkan tabel 10 di atas, rata-rata terendah yaitu karyawan PT Jasamarga Related Business menjawab setuju bahwa semua karyawan di kantor saya mempunyai tujuan yang sama untuk mencapai tujuan organisasi. Sementara rata-raat tertinggi yaitu karyawan PT Jasamarga Related Business menjawab setuju bahwa tempat saya bekerja mempunyai nilai yang sesuai dengan pribadi saya. Hal ini dapat dikatakan bahwa karyawan PT Jasamarga Related Business menyetujui dan berpendapat bahwa budaya organisasi atau tempat mereka melakukan kegiatan bekerja sudah sesuai dengan nilainilai yang mereka miliki.

Uji Validitas dan Reliabilitas

\section{Produktivitas Kerja}

Hasil analisa validitas terhadap 9 pernyataan yang diberikan kepada responden diperoleh hasil bahwa terdapat 8 pernyataan yang memiliki nilai r-hitung $>$ r-tabel, sehingga 8 pernyataan dinyatakan valid dan satu pernyataan dinyatakan tidak valid.

\section{Stress Kerja}

Hasil analisa validitas terhadap 9 pernyataan yang diberikan kepada responden memberikan hasil bahwa 7 pernyataan yang memiliki nilai ${ }_{\text {r-hitung }}>$ r-tabel, sehingga 7 pernyataan dinyatakan valid sementara 2 pernyataan lainnya dinyatakan tidak valid.

\section{Promosi Jabatan}

Hasil analisa validitas terhadap 9 pernyataan yang diberikan kepada responden memberikan hasil keseluruhan pernyataan yang memiliki nilai r-hitung $>$ r-tabel, sehingga keseluruhan pernyataan dinyatakan valid.

\section{Budaya Organisasi}

Berdasarkan analisa validitas terhadap 12 pernyataan yang diberikan kepada responden diperoleh hasil bahwa terdapat 11 pernyataan yang memiliki nilai ${ }_{\text {r-hitung }}>$ r-tabel, sehingga 11 pernyataan dinyatakan valid dan satu pernyataan dinyatakan tidak valid.

\section{Uji Reliabilitas}

Tabel 15 Uji Reliabilitas

\begin{tabular}{lccc}
\hline \multicolumn{1}{c}{ Variabel } & $\begin{array}{c}\text { Nilai Cronbach's } \\
\text { Alpha }\end{array}$ & $\begin{array}{c}\text { Tolak } \\
\text { Ukur }\end{array}$ & Keterangan \\
\hline Produktivitas Kerja (Y) & 0.687 & 0.6 & Reliabel \\
\hline Stress Kerja (X1) & 0.822 & 0.6 & Reliabel \\
\hline Promosi Jabatan (X2) & 0.758 & 0.6 & Reliabel \\
\hline Budaya Organisasi (X3) & 0.799 & 0.6 & Reliabel \\
\hline
\end{tabular}

Sumber: Data Diolah, SPSS, 2020.

Tabel 15 menunjukkan hasil perhitungan dari keseluruhan variabel memiliki nilai Cronbach's Alpha $(\alpha)>0.6$, maka keseluruhan variabel dinyatakan reliabel atau konsisten. 


\section{Model Summary}

\begin{tabular}{lllll} 
Model & $\mathrm{R}$ & $\mathrm{R}$ Square & $\begin{array}{l}\text { Adjusted } \\
\text { R Square }\end{array}$ & $\begin{array}{l}\text { Std. Error of } \\
\text { the Estimate }\end{array}$ \\
\hline 1 & $.693^{\mathrm{a}}$ & .480 & .453 & 2.773 \\
\hline
\end{tabular}

Organizational

Culture and Work

Productivity

a. Predictors: (Constant), Budaya Organisasi, Stress Kerja,

Promosi Jabatan

Sumber: Data Diolah, SPSS, 2020.

Tabel 16 menunjukkan nilai Adjusted R Square sebesar 0.453. Hal ini menunjukkan bahwa variabel $\mathrm{Y}$ atau independent, yang dalam penelitian ini adalah produktivitas kerja yang dapat dijelaskan atau mempengaruhi variabel $\mathrm{X}$ atau dependent yaitu variabel stress kerja, promosi jabatan dan budaya organisasi adalah sebesar 45,3\%. Sedangkan sisanya sebesar 0.547 atau $54.7 \%$ dipengaruhi oleh variabel lain.

Uji Hipotesis

\section{Uji T (Parsial)}

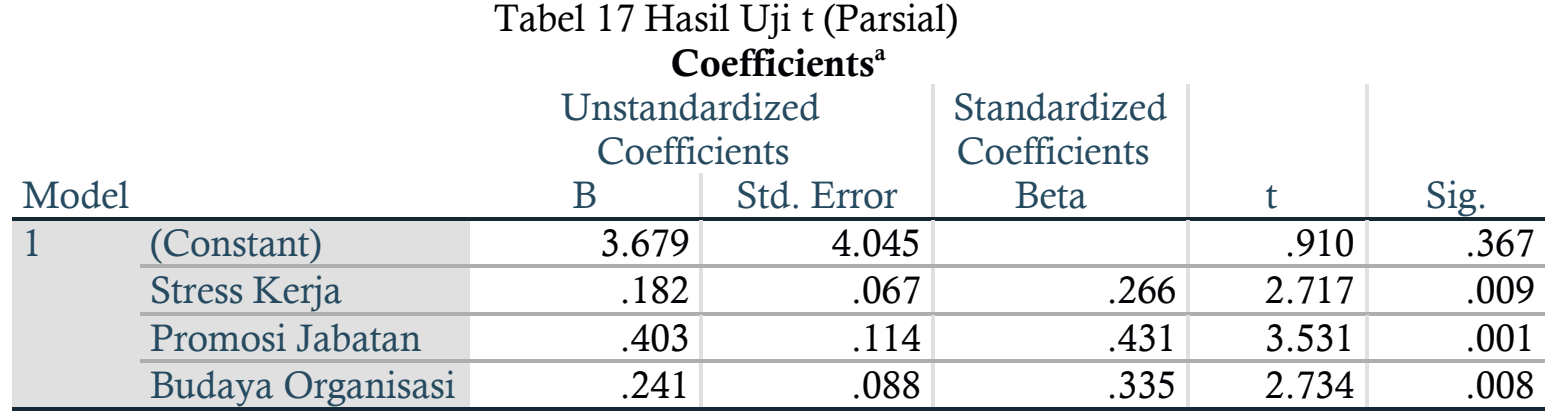

a. Dependent Variable: Produktivitas Kerja

Sumber: Data Diolah, SPSS, 2020.

a H1: Stress Kerja Berpengaruh terhadap Produktivitas Kerja

Tabel 17 menunjukkan nilai t-hitung variabel stress kerja lebih besar dari pada ttabel, yaitu $2.717>1.672$ dan nilai signifikasi variabel stress kerja lebih kecil dari probabilitas $5 \%$, yaitu $0.009<0.05$, sehingga dapat dikatakan bahwa stress kerja berpengaruh signifikan terhadap produktivitas kerja.

b H2: Promosi Jabatan Berpengaruh terhadap Produktivitas Kerja

Tabel 17 menunjukkan nilai t-hitung variabel promosi jabatan lebih besar dari pada t-tabel, yaitu $3.531>1.672$ dan nilai signifikasi variabel promosi jabatan lebih kecil dari probabilitas $5 \%$, yaitu $0.001<0.05$, sehingga dapat dikatakan bahwa promosi jabatan berpengaruh signifikan terhadap produktivitas kerja.

c H3: Budaya Organisasi Berpengaruh terhadap Produktivitas Kerja Tabel 17 menunjukkan nilai t-hitung variabel budaya organisasi lebih besar dari pada nilai t-tabel, yaitu $2.734>1.672$ dan nilai signifikasi variabel budaya organisasi lebih kecil dari probabilitas $5 \%$ yaitu $0.008<0.05$, sehingga dapat dikatakan bahwa budaya organisasi berpengaruh signifikan terhadap produktivitas kerja. 
Job Stress, Job

Promotion,

Organixational

Culture and Work

Productivity
2. Uji F (Simultan)

Tabel 18 Hasil Uji F (Simultan)

\begin{tabular}{|c|c|c|c|c|c|c|}
\hline \multicolumn{7}{|c|}{ ANOVA $^{\mathrm{a}}$} \\
\hline \multicolumn{2}{|c|}{ Model } & $\begin{array}{l}\text { Sum of } \\
\text { Squares }\end{array}$ & $\mathrm{df}$ & Mean Square & $\mathrm{F}$ & Sig. \\
\hline \multirow[t]{3}{*}{$\overline{1}$} & Regression & 398.035 & 3 & 132.678 & 17.257 & $.000^{\mathrm{b}}$ \\
\hline & Residual & 430.548 & 56 & 7.688 & & \\
\hline & Total & 828.583 & 59 & & & \\
\hline
\end{tabular}

a. Dependent Variable: Produktivitas Kerja

b. Predictors: (Constant), Budaya Organisasi, Stress Kerja, Promosi Jabatan

Sumber: Data Diolah, SPSS, 2020.

H4: Stress Kerja, Promosi Jabatan dan Budaya Organisasi berpengaruh secara

bersama-sama terhadap Produktivitas Kerja

Berdasarkan hasil uji F pada tabel 20, nilai F-hitung lebih besar dari pada F-tabel, yaitu $17.257>2.77$ dan nilai signifikasi lebih kecil dari 0.05 atau $0.000<0.05$ yang berarti bahwa stress kerja, promosi jabatan dan budaya organisasi berpengaruh signifikan secara bersama-sama terhadap produktivitas kerja.

\section{Pengaruh Stress Kerja Terhadap Produktivitas Kerja}

Dikarenakan hasil nilai t-hitung dan signifikasi sebesar $2.717>1.672$ dan $0.009<0.05$, maka dapat diambil keputusan Ho ditolak dan Ha diterima atau dengan kata lain stress kerja dapat berpengaruh signifikan terhadap produktivitas kerja karyawan.

Dengan kata lain, tingkat stress kerja yang dialami oleh karyawan PT Jasamarga Related Business adalah stress kerja yang bersifat positif. Hal ini dikarenakan para karyawan merasa termotivasi, bersemangat dan memiliki kepuasan kerja dalam melakukan pekerjaanya. Meskipun beban kerja dinilai cukup tinggi dan adanya pembagian jam kerja antara Work From Home (WFH) dan Work From Office (WFO), namun para karyawan tetap bekerja dengan baik dan semakin terpacu untuk bekerja lebih produktif lagi.

\section{Pengaruh Promosi Jabatan Terhadap Produktivitas Kerja}

Dikarenakan nilai t-hitung dan signifikasi sebesar $3.531>1.672$ dan $0.001<0.05$, maka dapat diambil kesimpulan Ho ditolak dan Ha diterima atau dengan kata lain promosi jabatan berpengaruh signifikan terhadap produktivitas kerja karyawan.

Maka dapat dikatakan promosi jabatan yang dilakukan di dalam PT Jasamarga Related Business dapat mempengaruhi hasil kerja karyawan atau tingkat produktivitas karyawan. Meskipun program promosi jabatan di dalam PT Jasamarga Related Business dinilai masih kurang dalam pelaksanaan dan implementasinya, namun jika program itu sedang dilaksanakan dapat menjadi pemicu motivasi karyawan untuk bekerja sebaik mungkin dan memaksimalkan kemampuan yang mereka punya.

\section{Pengaruh Budaya Organisasi Terhadap Produktivitas Kerja}

Dikarenakan nilai t-hitung dan signifikasi sebesar $2.734>1.672$ dan $0.008<0.05$, maka dapat diambil kesimpulan bahwa Ho ditolak dan Ha diterima atau dengan kata lain budaya organisasi berpengaruh signifikan terhadap produktivitas kerja karyawan.

Dengan kata lain, lingkungan kerja atau budaya organisasi yang ada di dalam PT Jasamarga Related Business dapat mendukung suasana kerja, baik dari segi peraturan di dalam perusahaan, rekan kerja, nilai budaya sampai dengan peringatan pada hari tertentu dinilai dapat menumbuhkan semangat kebersamaan dan kekeluargaan di dalam perusahaan. Dengan semakin meningkatnya rasa kebersamaan dan kekeluargaan di dalamnya, maka akan mendukung kerjasama yang baik antar karyawan yang kemudian akan mengingkatkan hasil kerja karyawan atau dapat meningkatkan produktivitas karyawan itu sendiri.

Pengaruh Stress Kerja, Promosi Jabatan dan Budaya Organisasi Berpengaruh Secara Bersama-sama Terhadap Produktivitas Kerja

Dilihat dari hasil perhitungan, nilai F-hitung dan signifikasi sebesar $17.257>2.77$ dan 
$0.000<0.05$, maka dapat diambil kesimpulan Ho ditolak dan Ha diterima atau dengan kata lain stress kerja, promosi jabatan dan budaya organisasi berpengaruh signifikan secara bersama-sama terhadap produktivitas kerja.

Hal ini dapat dilihat bahwa mayoritas responden memiliki jawaban yang mendukung terkait dengan variabel stress kerja, promosi jabatan dan budaya organisasi, seperti terpacu untuk lebih semangat bekerja akibat stress yang dialaminya, hasil kerja yang baik akan berpengaruh terhadap dipromosikanya seseorang dalam karirnya dan nilai yang dimiliki oleh perusahaan sesuai dengan nilai yang dimiliki oleh pribadi responden itu sendiri. Selain itu, ketiga variabel yang diuji secara parsial memiliki hasil berpengaruh terhadap produktivitas kerja, sehingga akan mempengaruhi uji $\mathrm{F}$ ini, yaitu ketiga variabel berpengaruh terhadap produktivitas kerja.

\section{PENUTUP}

Berdasarkan penelitian dan pengolahan data maka dapat disimpulkan sebagai berikut:

1. Stress kerja berpengaruh terhadap produktivitas kerja. Hal ini dapat dilihat dari tingkat stress kerja yang dimiliki oleh karyawan bersifat positif, dalam artian stress kerja yang dialami oleh karyawan bersifat membangun, memotivasi dan membuat karyawan menjadi bersemangat dalam melakukan pekerjaan. Memiliki beban kerja dan kepuasan dalam bekerja menjadi pemicu seorang karyawan mendapati stress yang bersifat positif. Dengan adanya tingkat stress yang dimiliki karyawan bersifat positif, maka karyawan akan memiliki tingkat produktivitas yang tinggi dikarenakan adanya semangat yang dapat memicu mereka untuk dapat bekerja lebih produktif lagi. Sehingga, dalam hal ini stress kerja berpengaruh terhadap produktivitas kerja.

2. Promosi jabatan berpengaruh terhadap produktivitas kerja. Hal ini dapat dilihat dari promosi jabatan dinilai mampu untuk membuat seorang karyawan dapat meningkatkan tingkat produktivitasnya dalam bekerja. Meskipun, promosi jabatan dinilai kurang diimplementasikan di dalam PT Jasamarga Related Business. Namun, jika program promosi sedang direncakan dan dijalankan, maka para karyawan berusaha untuk bekerja lebih baik lagi dan secara otomatis akan lebih produktif daripada biasanya agar mereka mendapatkan kesempatan utnuk dipromosikan. Sehingga, dalam hal ini promosi jabatan berpengaruh terhadap produktivitas kerja.

3. Budaya organisasi berpengaruh terhadap produktivitas kerja. Hal ini dapat dilihat dari suasana budaya organisasi atau lingkungan kerja di dalam PT Jasamarga Related Business yang mendukung, baik dari segi peraturan perusahaan, rekan kerja, nilai budaya sampai dengan peringatan pada hari tertentu yang kemudian akan menjadi dasar dimana rasa kebersamaan dan kekeluarga antar karyawan pun muncul. Dengan adanya rasa kebersamaan dan kekeluargaan ini, budaya antar karyawan menjadi terbentuk yang kemudian akan semakin mempermudah antar karyawan dalam bekerja, terutama dalam hal bekerja sama dan dalam membangun komunikasi yang baik dalam bekerja. Sehingga, dalam hal ini budaya organisasi berpengaruh terhadap produktivitas kerja.

4. Stress kerja, promosi jabatan dan budaya organisasi secara bersama-sama berpengaruh terhadap produktivitas kerja. Hal ini dapat dilihat dari ketiga variabel tersebut dinilai saling mempengaruhi satu sama lain terhadap produktivitas karyawan. Dengan karyawan yang memiliki tingkat motivasi dan semangat yang baik akibat stress dapat mempengaruhi produktivitas kerja, adanya program promosi yang akan dijalankan akan membuat karyawan menjadi semangat untuk bekerja dan juga dengan adanya rasa kebersamaan dan kekeluargaan antar karyawan membuat kerjasama dalam bekerja semakin tinggi yang kemudian menjadi saling support dan produktif satu sama lain. Sehingga, variabel stress kerja, promosi jabatan dan budaya organisasi secara bersama-sama mempengaruhi variabel produktivitas kerja.

\section{DAFTAR PUSTAKA}

[1] Afandi, Pandi. 2016. Concept \& Indicator Human Resource Management for Management Research. Yogyakarta: Deepublish Publisher.

[2] Anita, Anita. 2017. "Pengaruh Motivasi, Insentif Dan Promosi Jabatan Terhadap Produktivitas Kerja Karyawan Pada Bagian Penjualan Pt Kapuas Trio Tirta Sari
Job Stress, Job

Promotion,

Organizational

Culture and Work

Productivity

277 
Job Stress, Job

Promotion,

Organixational

Culture and Work

Productivity

278
Motor Di Kuala Kapuas." Jurnal Ilmiah Ekonomi Bisnis 3(3):436-42.

[3] Armstrong, Michael, and Stephen Taylor. 2014. Armstong's Handbook of Human Resource Management.

[4] Busro, Muhammad. 2018. Teori-Teori Manajemen Sumber Daya Manusia. Jakarta: Prenadamedia Group.

[5] Champoux, Joseph E. 2011. Organizational Behaviour. 4th ed. New York: Taylor \& Francis.

[6] Dessler, Gary. 2014. Manajemen Sumber Daya Manusia. 14th ed. Jakarta: Salemba Empat.

[7] Edison, Acep. 2015. MODUL PRAKTIKUM METODE RISET UNTUK BISNIS $D A N$ MANAJEMEN. Bandung: Universitas Widyatama.

[8] Elbadiansyah. 2019. Manajemen Sumber Daya Manusia. Purwokerto: CV IRDH.

[9] Hasibuan, Malayu S. P. 2016. Manajemen Sumber Daya Manusia. Revisi. Jakarta: PT Bumi Aksara.

[10] Hoboubi, Naser, Alireza Choobineh, Fatemeh Kamari Ghanavati, Sareh Keshavarzi, and Ali Akbar Hosseini. 2017. "The Impact of Job Stress and Job Satisfaction on Workforce Productivity in an Iranian Petrochemical Industry." Safety and Health at Work 8(1):67-71.

[11] Luthans, Fred. 2011. Organizational Behavior 12th Edition. New York: McGraw-Hill.

[12] Machado, Carolina. 2018. Organizational Behaviour and Human Resource Management. edited by J. P. Davim. Switzerland: Springer International Publishing.

[13] Margahana, Helisia, and Sri Sarwo Sari. 2019. "Analisis Promosi Jabatan Terhadap Produktivitas Kerja Karyawan Pada Pt. Fif Belitang Oku Timur." Jurnal AKTUAL 16(1):1.

[14] Mulyono. 2018. Berprestasi Melalui JFP Ayo Kumpulkan Angka Kredit. Yogyakarta: Deepublish Publisher.

[15] Sasuwe, Milla, Bernhard Tewal, Yantje Uhing, Jurusan Manajemen, Universitas Sam, and Ratulangi Manado. 2018. "Pengaruh Budaya Organisasi Dan Stres Kerja Terhadap Kepuasan Kerja Dan Produktivitas Kerja Karyawan Pt.Air Manado." Jurnal EMBA: Jurnal Riset Ekonomi, Manajemen, Bisnis Dan Akuntansi 6(4):2408-18.

[16] Selhub, Eva. 2019. The Stress Management Handbook. New York: Skyhorse Publishing.

[17] Siswanto, Eko. 2019. Rahasia Sukses Gaji, Promosi Jabatan Dan Mapan Finansial. Yogyakarta: Literasi Media Publishing.

[18] de Sivatte, Isabel, Judith R. Gordon, Pilar Rojo, and Ricardo Olmos. 2015. "The Impact of Work-Life Culture on Organizational Productivity." Personnel Review 44(6):883-905.

[19] Siyoto, Sandu, and Ali Sodik. 2015. Dasar Metodologi Penelitian. Yogyakarta: Literasi Media Publishing.

[20] Snell, Scott A., and Shad S. Morris. 2019. Managing Human Resource. 18th ed. USA: Cengage Learning.

[21] Yenita, Riski Novera. 2017. Higiene Industri. Yogyakarta: Deepublish Publisher. 